\title{
Extended Archaeal Histone-Based Chromatin Structure Regulates Global Gene Expression in Thermococcus kodakarensis
}

OPEN ACCESS

Edited by:

Changyi Zhang,

Carl R. Woese Institute for Genomic

Biology, University of Illinois at Urbana-Champaign, United States

Reviewed by:

Remus T. Dame,

Leiden University, Netherlands

Zhenfeng Zhang,

Institute of Microbiology, Chinese

Academy of Sciences, China

*Correspondence:

Thomas J. Santangelo

thomas.santangelo@colostate.edu

${ }^{\dagger}$ Present address: Alexandra M. Gehring, Arrakis Therapeutics, Waltham, MA,

United States

Specialty section This article was submitted to Biology of Archaea, a section of the journal

Frontiers in Microbiology

Received: 16 March 2021 Accepted: 12 April 2021

Published: 13 May 2021

Citation

Sanders TJ, Ullah F, Gehring AM,

Burkhart BW, Vickerman RL, Fernando S, Gardner AF, Ben-Hur A and Santangelo TJ (2021) Extended Archaeal Histone-Based Chromatin

Structure Regulates Global Gene Expression in Thermococcus kodakarensis.

Front. Microbiol. 12:681150. doi: 10.3389/fmicb.2021.681150
Travis J. Sanders ${ }^{1}$, Fahad Ullah ${ }^{2}$, Alexandra M. Gehring ${ }^{3+}$, Brett W. Burkhart ${ }^{1}$, Robert L. Vickerman', Sudili Fernando', Andrew F. Gardner ${ }^{3}$, Asa Ben-Hur' and Thomas J. Santangelo ${ }^{1 *}$

${ }^{1}$ Department of Biochemistry and Molecular Biology, Colorado State University, Fort Collins, CO, United States, ${ }^{2}$ Department of Computer Science, Colorado State University, Fort Collins, CO, United States, ${ }^{3}$ Molecular Enzymology Division, New England Biolabs, Inc., Ipswich, MA, United States

Histone proteins compact and organize DNA resulting in a dynamic chromatin architecture impacting DNA accessibility and ultimately gene expression. Eukaryotic chromatin landscapes are structured through histone protein variants, epigenetic marks, the activities of chromatin-remodeling complexes, and post-translational modification of histone proteins. In most Archaea, histone-based chromatin structure is dominated by the helical polymerization of histone proteins wrapping DNA into a repetitive and closely gyred configuration. The formation of the archaeal-histone chromatin-superhelix is a regulatory force of adaptive gene expression and is likely critical for regulation of gene expression in all histone-encoding Archaea. Single amino acid substitutions in archaeal histones that block formation of tightly packed chromatin structures have profound effects on cellular fitness, but the underlying gene expression changes resultant from an altered chromatin landscape have not been resolved. Using the model organism Thermococcus kodakarensis, we genetically alter the chromatin landscape and quantify the resultant changes in gene expression, including unanticipated and significant impacts on provirus transcription. Global transcriptome changes resultant from varying chromatin landscapes reveal the regulatory importance of higher-order histone-based chromatin architectures in regulating archaeal gene expression.

Keywords: archaea, histone, chromatin, transcriptome, Thermococcus, RNA-seq

\section{INTRODUCTION}

Most Archaea encode histone proteins to organize their DNA into a protein:DNA complex known as chromatin (Sandman and Reeve, 2000, 2001, 2006; Peeters et al., 2015; Mattiroli et al., 2017; Bhattacharyya et al., 2018; Henneman et al., 2018; Sanders et al., 2019b; Henneman et al., 2020; Stevens et al., 2020; Bowerman et al., 2021; Laursen et al., 2021). The organization and tractability of chromatin structure is essential to regulate adaptive gene expression (Wilkinson et al., 2010; Nalabothula et al., 2013; Mattiroli et al., 2017). Archaeal and eukaryotic histone proteins are highly homologous, sharing conserved residues that contact DNA and retain structural elements of the 
histone fold (Sandman and Reeve, 2000; Soares et al., 2000; Mattiroli et al., 2017). In most cases, however, the extensions or tails common to eukaryotic histones are not present in archaeal histone isoforms (Peeters et al., 2015; Mattiroli et al., 2017; Nishida and Oshima, 2017; Bhattacharyya et al., 2018; Henneman et al., 2018; Henneman et al., 2020; Sanders et al., 2019b; Stevens et al., 2020). Unlike their eukaryotic counterparts, archaeal histones can homodimerize and spontaneously oligomerize to form chromatin with a single protein (Decanniere et al., 2000; Mattiroli et al., 2017; Bhattacharyya et al., 2018; Henneman et al., 2020; Stevens et al., 2020; Bowerman et al., 2021; Laursen et al., 2021), and thus unlike their eukaryotic counterparts (Luger et al., 1997), archaeal chromatin structures are not defined in size. Continued polymerization of archaeal histone proteins produces a symmetrical superstructure composed of increasing lengths of DNA wrapped around a core of polymerized histone dimers (Mattiroli et al., 2017). This extended histone-based chromatin structure, alternatively termed the hypernucleosome (Bhattacharyya et al., 2018; Henneman et al., 2018; Henneman et al., 2020), is the biological form of archaeal chromatin within which gene expression is regulated (Figure 1A).

The polymerization of histone dimers in Archaea does not resemble the nucleosome-nucleosome interactions observed in eukaryotes (Luger et al., 1997; Mattiroli et al., 2017; Sanders et al., 2019b; Henneman et al., 2020; Stevens et al., 2020; Bowerman et al., 2021). Alignments and analyses of unique archaeal histone sequences reveals the vast majority of archaeal histone proteins retain only the residues comprising the core eukaryotic histone-fold and that many amino acids are highly conserved in positions that form the histone-fold or mediate DNA interactions (Mattiroli et al., 2017; Nishida and Oshima, 2017; Zaremba-Niedzwiedzka et al., 2017; Henneman et al., 2020; Stevens et al., 2020). The core histone fold, common to eukaryotic and archaeal histones, consists of three alpha helices ( $\alpha 1, \alpha 2$, and $\alpha 3)$ connected through two flexible loops (L1 and L2). A conserved alanine-glycine-alanine (AGA) motif in L1 was identified that was not obviously involved in protein-DNA interactions or in supporting the core histone-fold (Mattiroli et al., 2017; Bhattacharyya et al., 2018; Henneman et al., 2018; Henneman et al., 2020; Stevens et al., 2020) (Figure 1B). The crystal structure of archaeal histone-based chromatin provided the first clues to the importance of the highly conserved motif in L1, wherein the small side chains of these nearly invariant amino acids permitted the close proximity of adjacent gyres of DNA within the superhelix at the Loop1-Loop1 (L1-L1) interface. The conservation of these residues was thus hypothesized to support the biologically important, tight-packing of archaeal histone-based chromatin architectures (Mattiroli et al., 2017; Bhattacharyya et al., 2018; Henneman et al., 2018; Henneman et al., 2020; Stevens et al., 2020).

Archaeal histone-based chromatin digestion patterns reveal the existence of histone-DNA superstructures that vary in length from protection of $\sim 60$ bp of DNA by a histone tetramer to protection of $\sim 300$ bp of DNA by a semi-continuous polymer of $\sim 10$ symmetrically bound histone dimers. Given the different lengths and proposed dynamic structures of archaeal histone-based chromatin, we adopt the term archaeal histonebased chromatin polymers (AHCPs) to denote histone:DNA superstructures wherein each additional histone dimer can wrap 230 bp of DNA to extend the AHCP (Nalabothula et al., 2013; Mattiroli et al., 2017; Bhattacharyya et al., 2018; Sanders et al., 2019a; Bowerman et al., 2021). While dynamic changes in AHCPs are expected, particularly in species with multiple histone isoforms (Henneman et al., 2020; Stevens et al., 2020), it is also likely that specific DNA sequences and loci are more likely to retain extended AHCPs that are important for regulating gene expression (Čuboňová et al., 2012; Nalabothula et al., 2013; Dulmage et al., 2015). Although the presence of several histone isoforms in many Archaea suggests the potential for variation in superhelix composition and length (Mattiroli et al., 2017; Bhattacharyya et al., 2018; Henneman et al., 2018; Sanders et al., 2019b; Henneman et al., 2020; Stevens et al., 2020; Bowerman et al., 2021), the viability of strains with only a single histone demonstrate that even homopolymers permit formation of AHCPs in vivo (Sandman and Reeve, 2001, 2006; Santangelo et al., 2009; Čuboňová et al., 2012; Dulmage et al., 2015). The biological importance of AHCPs is supported by the evolutionary retention of the AGA motif in L1 which permits close association of adjacent superhelical gyres. Importantly, allelic substitutions of the central glycine within the L1-AGA motif abrogated formation of extended AHCPs, decreased cellular fitness and resulted in the loss of adaptive gene expression when actively growing cultures were moved to a new metabolic environment (Jäger et al., 2014; Mattiroli et al., 2017).

The importance of AHCPs in modulating gene expression suggests unique archaeal gene regulation strategies that take advantage of mechanisms to retain or abolish extended archaeal histone-based chromatin structures (Sanders et al., 2019b; Stevens et al., 2020; Bowerman et al., 2021). To evaluate the normal contribution of AHCPs to gene regulation, we generated strains of the model archaeon Thermococcus kodakarensis (Farkas et al., 2013; Gehring et al., 2017; Atomi and Reeve, 2019) wherein genomically encoded histone variants impacted global genomic architecture and quantified the gene expression changes resultant from modified AHCP architectures. T. kodakarensis normally encodes two closely related histone isoforms, termed Histone A (HTkA) and Histone B (HTkB), but strains encoding only a single histone variant are viable (Čuboňová et al., 2012; Mattiroli et al., 2017; Sanders et al., 2019b). To evaluate the consequences of altering AHCPs in archaeal cells, strains of T. kodakarensis were constructed to encode only HTkA in WT form (HTkA ${ }^{W T}$; $\triangle \mathrm{HTkB}$ ), only HTkA with a single amino acid substitution G17D $\left(\mathrm{HTkA}^{G 17 D} ; \Delta \mathrm{HTkB}\right)$, or retain HTkB in WT form and express $\mathrm{HTkA}^{G 17 D}\left(\mathrm{HTkA}^{G 17 D} ; \Delta \mathrm{HTkB}^{W T}\right)$. Substitution of just a single residue, G17, is sufficient to disrupt AHCP formation in vivo beyond $\sim 90$ bp by inhibiting the close association of adjacent gyres of AHCPs (Bhattacharyya et al., 2018). We report here that retention of a single WT histone variant is sufficient to maintain extended AHCPs in archaeal cells, but extended AHCPs are abolished in strains encoding only the mutated AGA motif, $\mathrm{HTkA}^{G 17 D}$.

We demonstrate here, using comparative differential RNAseq analyses of strains with unique AHCP landscapes, that 
A

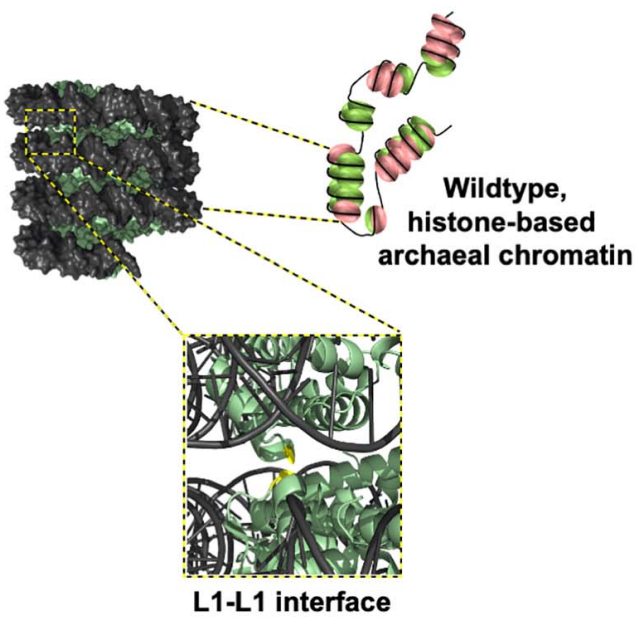

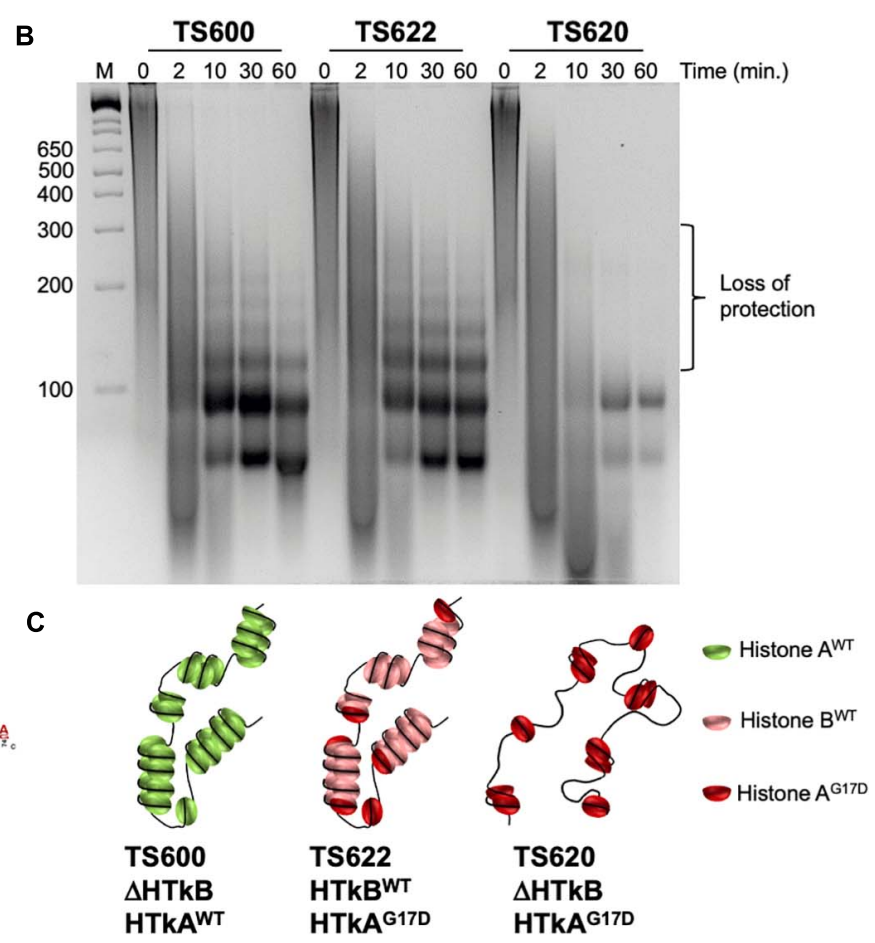

FIGURE 1 | A single wild-type histone protein is sufficient for normal DNA protection in T. kodakarensis. (A) Diagrammatic representation of wildtype chromatin modeled from the archaeal histone-based chromatin crystal structure: 9 polymerized histone B dimers (pale green) wrapped by DNA (gray) adapted from Mattiroli et al. (2017). The central glycine in the AGA motif at the Loop1-Loop1 interface is colored in red. A Logo-plot highlights the conservation of this motif. Histone dimers may be heterogeneously composed. (B) DNA fragments resulting from micrococcal nuclease (MNase) digested chromatin demonstrate the state of chromatin structure in TS600, TS622, and TS620. Chromatin purified from TS600 (TK1413 ${ }^{W T}$ :histone A/ $\Delta$ TK2289:histone B) resists MNase digestion over time, resulting in a laddered DNA banding pattern. Prominent 60 and 90 bp bands in addition to higher molecular weight bands (increasing 30 bp increments up to 300 bp) represent varying levels of histone dimerization and MNase protection. Chromatin purified from TS622 (TK1413G17D:histone ATK2289WT:histone B) exhibits an identical protection pattern to TS600 despite encoding a variant (G17D) histone A. This suggests a single WT histone is sufficient for normal chromatin structure formation. Chromatin purified from TS620 (TK1413G17D :histone AVATK2289:histone B) exhibits a markedly different protection pattern from TS600 and TS622. The presence of only a variant (G17D) histone A results in a loss of DNAs protected above $90 \mathrm{bp}$, demonstrating the disruption of the L1-L1 interface interferes with continued histone dimer polymerization. (C) Diagrammatic representation of the potential chromatin structures in TS600, TS622, and TS620.

substantial and genome-wide variations in gene expression result from alternating archaeal histone-based chromatin structures, underscoring the importance of AHCPs in normal regulation of gene expression. Expression differences observed in strains lacking extended AHCPs suggest architectural changes in AHCPs are most impactful for the proper regulated expression of chemotaxis-, motility- and proviral-encoding regions of the genome. The global regulatory potential of AHCPs is confirmed and offers impactful routes to control archaeal gene expression by modulating chromatin architectures and AHCP formation in vivo.

\section{MATERIALS AND METHODS}

\section{Strain Construction and Growth Conditions}

Thermococcus kodakarensis strains were constructed essentially as previously described (Gehring et al., 2017). While T. kodakarensis strains deleted for either TK2289 or TK1413 remain viable, strains deleted for TK1413 are no longer genetically accessible (Čuboňová et al., 2012). Thus, to generate single histone-encoding strains with substitutions that impact AHCP formation, we first deleted TK2289, then introduced allelic changes to TK1413. T. kodakarensis strain TS600 was constructed from parental strain TS559 by markerless deletion of TK2289 (HTkB). Strain TS622 was constructed from TS600 by allelic substitution of TK1413 (HTkA) for TK1413 G17D $\left(\mathrm{HTkA}^{G 17 D}\right)$. TS620 was constructed by markerless deletion of TK2289 (HTkB) from TS622. Allelic substitution of TK1413 for TK1413 ${ }^{G 17 D}$ was confirmed by PCR amplification of the TK1413 loci and subsequent sequencing while deletion of TK2289 was confirmed via diagnostic PCR with primers flanking TK2289. Cultures were grown at $85^{\circ} \mathrm{C}$ in artificial seawater (ASW) supplemented with $0.5 \%(\mathrm{w} / \mathrm{v})$ tryptone, $0.5 \%(\mathrm{w} / \mathrm{v})$ yeast extract (ASW-YT), trace mineral solution and vitamin mixture (nutrient rich medium). ASW contains, per 1, $20 \mathrm{~g} \mathrm{NaCl}, 3 \mathrm{~g} \mathrm{MgCl}_{2} \cdot 6 \mathrm{H}_{2} \mathrm{O}$, $6 \mathrm{~g} \mathrm{MgSO}_{4} \cdot 7 \mathrm{H}_{2} \mathrm{O}, 1 \mathrm{~g}\left(\mathrm{NH}_{4}\right)_{2} \mathrm{SO}_{4}, 200 \mathrm{mg} \mathrm{NaHCO} 3,300 \mathrm{mg}$ $\mathrm{CaCl}_{2} \cdot 2 \mathrm{H}_{2} \mathrm{O}$, $0.5 \mathrm{~g} \mathrm{KCl}, 420 \mathrm{mg} \mathrm{KH}_{2} \mathrm{PO}_{4}, 50 \mathrm{mg} \mathrm{NaBr}$, $20 \mathrm{mg} \mathrm{SrCl}_{2} \cdot 6 \mathrm{H}_{2} \mathrm{O}$, and $10 \mathrm{mg} \mathrm{Fe}\left(\mathrm{NH}_{4}\right)_{2}\left(\mathrm{SO}_{4}\right) 2 \cdot 6 \mathrm{H}_{2} \mathrm{O}$. The trace mineral solution $(1,000 \times)$ contains, per $1,0.5 \mathrm{~g}$ $\mathrm{MnSO}_{4} 6 \mathrm{H}_{2} \mathrm{O}, 0.1 \mathrm{~g} \mathrm{CoCl} \cdot 6 \mathrm{H}_{2} \mathrm{O}, 0.1 \mathrm{~g} \mathrm{ZnSO} \cdot \cdot 7 \mathrm{H}_{2} \mathrm{O}, 0.01 \mathrm{~g}$ 
A

\begin{tabular}{|l|l|l|l|}
\hline Strain & $\begin{array}{l}\text { Number of downregulated } \\
\text { genes }(\geq 2 \text { fold decrease })\end{array}$ & $\begin{array}{l}\text { Number of } \\
\text { unchanged genes }\end{array}$ & $\begin{array}{l}\text { Number of upregulated genes } \\
(\geq 2 \text { fold increase })\end{array}$ \\
\hline TS620 & 100 & 1991 & 134 \\
\hline TS622 & 49 & 2164 & 18 \\
\hline
\end{tabular}

B

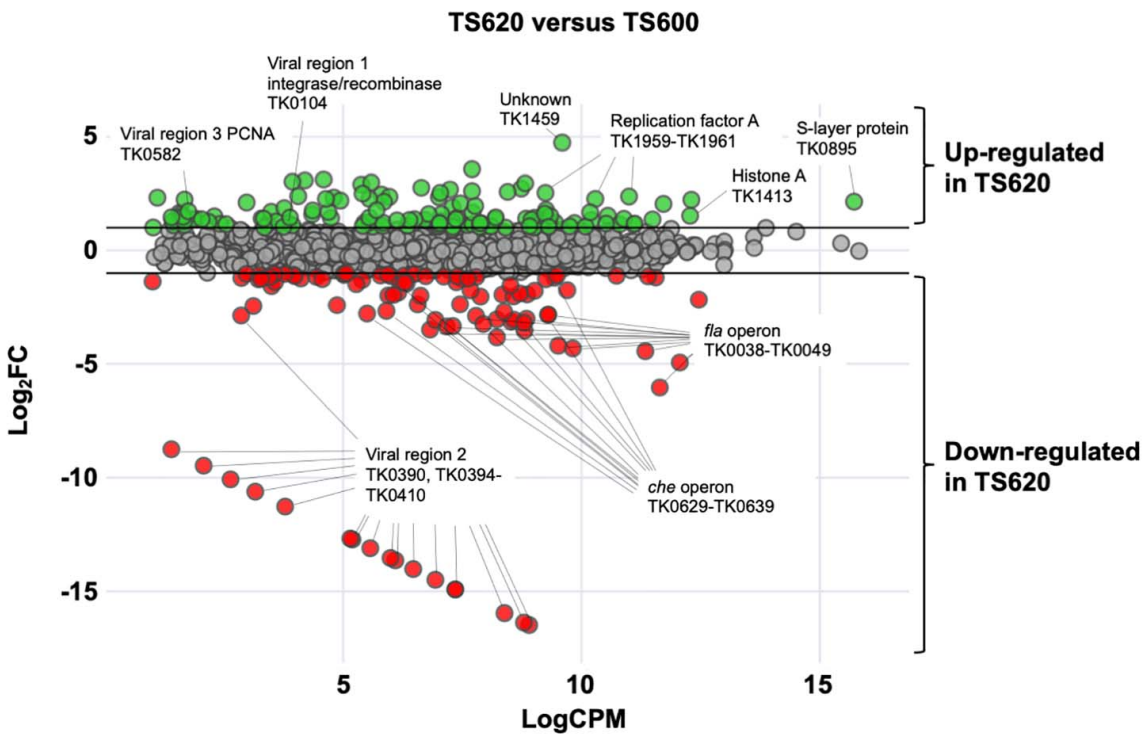

C

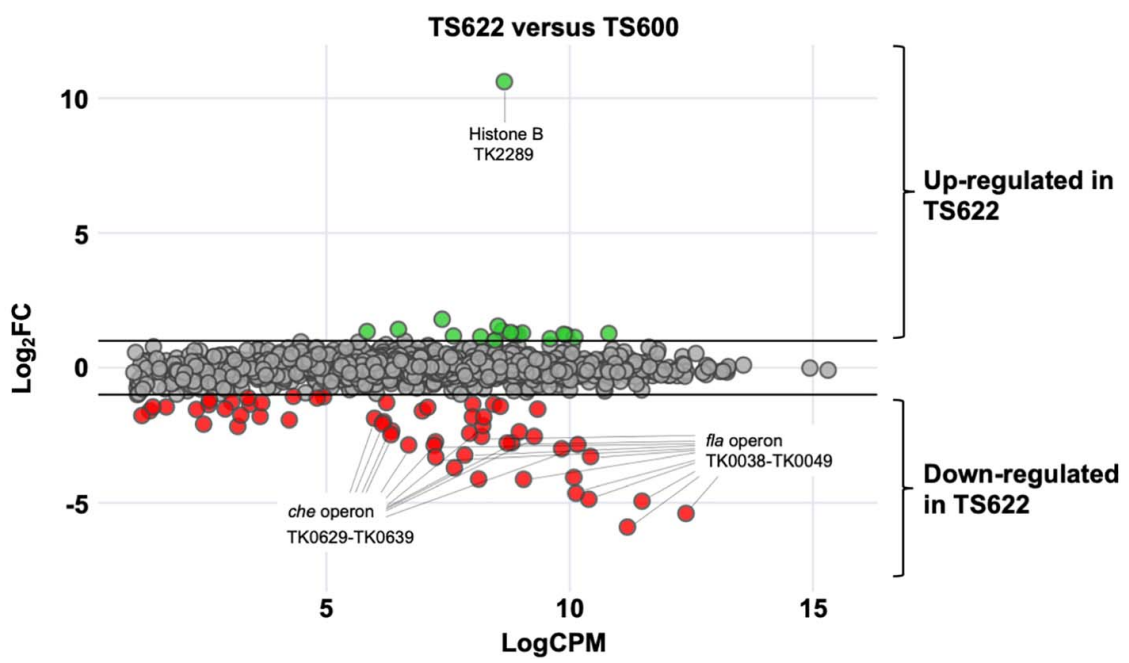

FIGURE 2 | Altering 3-dimensional chromatin structure dramatically alters gene expression in T. kodakarensis. (A) In TS620 (compared to TS600) 100 protein-coding genes were downregulated while 134 protein-coding genes were upregulated. In TS622 (compared to TS600), 49 protein-coding genes were downregulated while 18 protein-coding genes were upregulated. (B) In TS620 (TK1413G17D:histone A/ $\Delta$ TK2289:histone B) differential RNA-sequencing, represented in an MA plot, revealed a number of genes are significantly upregulated and downregulated when compared to TS600 (TK1413 ${ }^{W T}$ : histone AVATK2289:histone B). Green transcripts are significantly ( $\geq 2$ fold change) enriched in TS620 when compared to TS600. Red transcripts are significantly depleted ( $\geq 2$ fold change) in TS620 when compared to TS600. Notably, in TS620, a number of single stranded binding proteins (TK1959-1961: replication protein A subunits Rpa32, Rpa14, and Rpa41) are significantly enriched in TS620. TK1413 G17D was found to be enriched in TS620 when compared to TK1413 ${ }^{W T}$ in TS600. In TS620 transcripts involved in cell motility and cell signaling (TK0038-TK0049: archaeal Fla operon and archaeal che operon (TK0629-TK0639) were significantly depleted. Additionally, a portion (TK0394-TK0410) of viral region 2 (TK0381-TK0421) was significantly depleted. (C) In TS622 (TK1413G17D:histone ATK2289WT:histone B) far fewer genes were upregulated when compared to TS600. Downregulated genes related in cell motility and environmental signal sensing revealed similar trends to TS620 (che and fla operons). 
TABLE T1A | Transcripts enriched and depleted in TS620 (TK1413 G17D:histone A $\Delta$ TK2289:histone B) compared to TS600 (TK1413WT:histone

A $\Delta$ TK2289:histone B). (A) The 30 most enriched transcripts in TS620 compared to TS600. (B) The 30 most depleted transcripts (sans viral region 2 transcripts) in TS620 compared to TS600.

\begin{tabular}{|c|c|c|c|}
\hline \multicolumn{4}{|l|}{ A } \\
\hline Transcript & Annotation & Process & Fold Change \\
\hline TK1459 & Hypothetical protein & Unknown & 22.52 \\
\hline TK1358 & Hypothetical protein & Unknown & 21.63 \\
\hline TK2061 & $\begin{array}{l}\text { Sodium/phosphate } \\
\text { symporter }\end{array}$ & Transport & 12.84 \\
\hline TK0604 & Hypothetical protein & $\begin{array}{l}\text { Unknown, viral } \\
\text { region } 3\end{array}$ & 12.00 \\
\hline TK0605 & Hypothetical protein & $\begin{array}{l}\text { Unknown, viral } \\
\text { region } 3\end{array}$ & 9.75 \\
\hline TK0208 & $\begin{array}{l}\text { Phosphoribosyl } \\
\text { formylglycinamidine } \\
\text { cyclo-igase }\end{array}$ & Purine metabolism & 9.51 \\
\hline TK0202 & $\begin{array}{l}\text { Phosphoribosyl } \\
\text { formylglycinamidine } \\
\text { ynthase, PurS } \\
\text { component }\end{array}$ & Purine metabolism & 9.18 \\
\hline TK0204 & $\begin{array}{l}\text { Phosphoribosylamine- } \\
\text { glycine } \\
\text { ligase }\end{array}$ & Purine metabolism & 8.97 \\
\hline TK1392 & NADH oxidase & Metabolsim & 8.74 \\
\hline TK0203 & $\begin{array}{l}\text { Phosphoribosyl } \\
\text { formylglycinamidine } \\
\text { cyclo-ligase }\end{array}$ & Purine metabolism & 8.43 \\
\hline TK1356 & ATPase, AAA superfamily & $\begin{array}{l}\text { Unknown, viral } \\
\text { region } 4\end{array}$ & 8.41 \\
\hline TK0835 & $\begin{array}{l}\text { Phosphoribosy } \\
\text { laminoimidazole } \\
\text { carboxylase, ATPase } \\
\text { subunit }\end{array}$ & Purine metabolism & 760 \\
\hline TK1393 & $\begin{array}{l}\text { Anaerobic glycerol } \\
\text { 3-phosphate } \\
\text { dehydrogenase }\end{array}$ & Lipid metabolism & 7.40 \\
\hline TK2060 & $\begin{array}{l}\text { Distant homolog of } \\
\text { phosphate transport } \\
\text { system regulator PhoU }\end{array}$ & Transport & 7.20 \\
\hline TK1391 & $\begin{array}{l}\text { Molybdopterin } \\
\text { oxidoreductase, } 4 \mathrm{Fe}-4 \mathrm{~S} \\
\text { cluster-binding subunit }\end{array}$ & Central metabolsim & 6.81 \\
\hline TK1023 & Hypothetical protein & Unknown & 6.64 \\
\hline TK0207 & $\begin{array}{l}\text { Format-dependent } \\
\text { hosphoribosylglycinamide } \\
\text { formyltransferase }\end{array}$ & Purine metabolism & 6.42 \\
\hline TK1960 & $\begin{array}{l}\text { Replication factor } A \\
\text { complex, RPA14 subunit }\end{array}$ & $\begin{array}{l}\text { Replication/recombi } \\
\text { nation/repair }\end{array}$ & 6.42 \\
\hline TK0201 & $\begin{array}{l}\text { Phosphoribosy } \\
\text { Iformylglycinamidine } \\
\text { synthase I }\end{array}$ & Purine metabolism & 6.26 \\
\hline TK1464 & Hypothetical protein & Unknown & 6.05 \\
\hline TK0599 & Hypothetical protein & $\begin{array}{l}\text { Unknown, viral } \\
\text { region } 3\end{array}$ & 5.70 \\
\hline TK1959 & $\begin{array}{l}\text { Replication factor A } \\
\text { complex, RPA32 subunit }\end{array}$ & $\begin{array}{l}\text { Replication/recombi } \\
\text { nation/repair }\end{array}$ & 5.63 \\
\hline TK0389 & Hypothetical protein & $\begin{array}{l}\text { Unknown, viral } \\
\text { region } 2\end{array}$ & 5.57 \\
\hline
\end{tabular}

TABLE T1A | Continued

\begin{tabular}{lllc}
\hline A & & & \\
\hline Transcript & Annotation & Process & Fold Change \\
\hline TK0252 & $\begin{array}{l}\text { Indole-3-glycerol } \\
\text { phosphate synthase } \\
\text { Phosphoribosyl } \\
\text { aminoimidazole } \\
\text { TK0836 }\end{array}$ & $\begin{array}{l}\text { Amino acid } \\
\text { synthesis } \\
\text { Purine metabolism }\end{array}$ & 5.57 \\
& $\begin{array}{l}\text { subunit } \\
\text { ATPase, AAA superfamily }\end{array}$ & $\begin{array}{l}\text { Unknown, viral } \\
\text { region 3 }\end{array}$ & 5.50 \\
TK0601 & Hypothetical protein & $\begin{array}{l}\text { Unknown, viral } \\
\text { region 3 }\end{array}$ & 5.39 \\
TK0580 & Hypothetical protein & $\begin{array}{l}\text { Unknown, viral } \\
\text { region 2 }\end{array}$ & 5.17 \\
TK0382 & $\begin{array}{l}\text { Replication/recombi } \\
\text { neplication factor A } \\
\text { TK1961 }\end{array}$ & 5.14 \\
TK0600 & Hypothetical protein & $\begin{array}{l}\text { Unknown, viral } \\
\text { region 3 }\end{array}$ & 5.13 \\
& & & \\
\hline
\end{tabular}

$\mathrm{CuSO}_{4} \cdot 5 \mathrm{H}_{2} \mathrm{O}, 0.01 \mathrm{~g} \mathrm{AlK}\left(\mathrm{SO}_{4}\right)_{2} \cdot 12 \mathrm{H}_{2} \mathrm{O}, 0.01 \mathrm{~g} \mathrm{H}_{3} \mathrm{BO}_{3}$, and $0.01 \mathrm{~g} \mathrm{Na}_{2} \mathrm{MoO}_{4} \cdot 2 \mathrm{H}_{2} \mathrm{O}$. The vitamin mixture $(200 \times)$ contains, per l, $0.2 \mathrm{~g}$ niacin, $0.08 \mathrm{~g}$ biotin, $0.2 \mathrm{~g}$ pantothenate, $0.2 \mathrm{~g}$ lipoic acid, $0.08 \mathrm{~g}$ folic acid, $0.2 \mathrm{~g}$ p-aminobenzoic acid, $0.2 \mathrm{~g}$ thiamine, $0.2 \mathrm{~g}$ riboflavin, $0.2 \mathrm{~g}$ pyridoxine, and $0.2 \mathrm{~g}$ cobalamin. When present, sodium pyruvate was added at $5 \mathrm{~g}$ per l, agmatine sulfate to $1 \mathrm{mM}$ and 6- methyl purine (6MP) to $100 \mu \mathrm{M}$ (ASW-YT-Pyr). Elemental sulfur (So) was added at $2 \mathrm{~g}$ per 1 in liquid media (ASW-YT-) but was replaced by polysulfides in solid media. Polysulfide solution $(500 \times)$ contained, per $1,66.7 \mathrm{~g}$ sodium sulfide $\left(\mathrm{Na}_{2} \mathrm{~S} \cdot 9 \mathrm{H}_{2} \mathrm{O}\right)$ and $3 \mathrm{~g}$ sulfur. Gelrite was added to $1 \%$ $(\mathrm{w} / \mathrm{v})$ to solidify media.

\section{Chromatin Isolation and Micrococcal Nuclease Digestion}

Chromatin isolation and micrococcal nuclease digestions were adapted from Mattiroli et al. (2017). Strains TS600, TS620 and TS622 were individual grown to an optical density (measured at $600 \mathrm{~nm}$ ) of $\sim 0.5$ in liquid ASW-YT-S and each starter culture was used to inoculate $(1: 100) 200 \mathrm{ml}$ of ASW-YT-Pyr cultures that were allowed to grow to an optical density (measured at $600 \mathrm{~nm}$ ) of $\sim 0.5$ to encourage chromatin reprograming. Cultures were pelleted at $\sim 8,000 \times g$ and immediately frozen at $-80^{\circ} \mathrm{C}$. Cell pellets were resuspended in $1.0 \mathrm{~mL}$ of MNase buffer (50 mM Tris- $\mathrm{HCl} \mathrm{pH} \mathrm{8.0,100} \mathrm{mM} \mathrm{NaCl,} \mathrm{and} 1 \mathrm{mM}$ $\mathrm{CaCl}_{2}$ ) per $0.2 \mathrm{~g}$ of cell mass and ground to homogeneity with a mortar and pestle. Homogenized cells were mechanically lysed by repeated liquid nitrogen freezing and subsequent grinding five times. Whole cell lysate was gently clarified at $1,700 \times g$ for $5 \mathrm{~min}$ and the chromatin containing clarified lysate was RNase A digested (Sigma, 4,000 U) for $1 \mathrm{~h}$ at $37^{\circ} \mathrm{C} . \sim 1,500$ $\mathrm{U}$ of micrococcal nuclease (New England Biolabs) was added to chromatin and aliquots $(\sim 100 \mu \mathrm{l})$ of digested DNAs were extracted by the addition of $300 \mu \mathrm{l}$ of $10 \mathrm{mM}$ Tris- $\mathrm{HCl} \mathrm{pH}$ 8.0 and $400 \mu \mathrm{l}$ of phenol/chloroform/isoamyl alcohol (25:24:1). Following thorough emulsion and centrifugation at 10,000 $\times g$ 
TABLE T1B

B

\begin{tabular}{|c|c|c|c|}
\hline Transcript & Annotation & Process & Fold chang \\
\hline TK0038 & $\begin{array}{l}\text { Archaeal flagellin B1 } \\
\text { precursor }\end{array}$ & Cell motility & -65.39 \\
\hline TK0039 & $\begin{array}{l}\text { Archaeal flagellin B2 } \\
\text { precursor }\end{array}$ & Cell motility & -30.65 \\
\hline TK0040 & $\begin{array}{l}\text { Archaeal flagellin B3 } \\
\text { precursor }\end{array}$ & Cell motility & -21.73 \\
\hline TK0042 & $\begin{array}{l}\text { Archaeal flagellin B5 } \\
\text { precursor }\end{array}$ & Cell motility & -19.94 \\
\hline TK0041 & $\begin{array}{l}\text { Archaeal flagellin B4 } \\
\text { precursor }\end{array}$ & Cell motility & -18.37 \\
\hline TK0043 & $\begin{array}{l}\text { Archaeal } \\
\text { flagella-related } \\
\text { protein C }\end{array}$ & Cell motility & -14.30 \\
\hline TK0044 & $\begin{array}{l}\text { Archaeal } \\
\text { flagella-related } \\
\text { protein D, internal } \\
\text { insertion }\end{array}$ & Cell motility & -11.59 \\
\hline TK0045 & $\begin{array}{l}\text { Archaeal } \\
\text { flagella-related } \\
\text { protein } \mathrm{F}\end{array}$ & Cell motility & -11.25 \\
\hline TK0046 & $\begin{array}{l}\text { Archaeal } \\
\text { flagella-related } \\
\text { protein } \mathrm{G}\end{array}$ & Cell motility & -10.23 \\
\hline TK0632 & $\begin{array}{l}\text { Chemotaxis response } \\
\text { regulator, CheY }\end{array}$ & $\begin{array}{l}\text { Environmental } \\
\text { information processing }\end{array}$ & -10.09 \\
\hline TK0631 & $\begin{array}{l}\text { Chemotaxis protein } \\
\text { methyltransferase, } \\
\text { CheR }\end{array}$ & $\begin{array}{l}\text { Environmental } \\
\text { information processing }\end{array}$ & -9.51 \\
\hline TK0634 & $\begin{array}{l}\text { Chemotaxis histidine } \\
\text { kinase, CheA }\end{array}$ & $\begin{array}{l}\text { Environmental } \\
\text { information processing }\end{array}$ & -9.16 \\
\hline TK0633 & $\begin{array}{l}\text { Chemotaxis } \\
\text { protein-glutamate } \\
\text { methylesterase, } \\
\text { containing receiver } \\
\text { domain }\end{array}$ & $\begin{array}{l}\text { Environmental } \\
\text { information processing }\end{array}$ & -8.81 \\
\hline TK0635 & $\begin{array}{l}\text { Chemotaxis histidine } \\
\text { kinase }\end{array}$ & $\begin{array}{l}\text { Environmental } \\
\text { information processing }\end{array}$ & -8.39 \\
\hline TK0156 & $\begin{array}{l}\text { Methyl-accepting } \\
\text { chemotaxis protein }\end{array}$ & $\begin{array}{l}\text { Environmental } \\
\text { information processing }\end{array}$ & -8.34 \\
\hline TK2147 & $\begin{array}{l}\text { Methyl-accepting } \\
\text { chemotaxis protein }\end{array}$ & $\begin{array}{l}\text { Environmental } \\
\text { information processing }\end{array}$ & -8.25 \\
\hline TK0049 & $\begin{array}{l}\text { Archaeal } \\
\text { flagella-related } \\
\text { membrane protein J }\end{array}$ & Cell motility & -8.09 \\
\hline TK0047 & $\begin{array}{l}\text { Archaeal } \\
\text { flagella-related } \\
\text { protein } \mathrm{H}\end{array}$ & Cell motility & -7.39 \\
\hline TK0630 & $\begin{array}{l}\text { Methyl-accepting } \\
\text { chemotaxis protein }\end{array}$ & $\begin{array}{l}\text { Environmental } \\
\text { information processing }\end{array}$ & -7.14 \\
\hline TK0048 & $\begin{array}{l}\text { Archaeal } \\
\text { flagella-related } \\
\text { protein I }\end{array}$ & Cell motility & -7.13 \\
\hline TK0637 & $\begin{array}{l}\text { Chemotaxis protein } \\
\text { cheC }\end{array}$ & $\begin{array}{l}\text { Environmental } \\
\text { information processing }\end{array}$ & -6.89 \\
\hline TK0050 & $\begin{array}{l}\text { Hypothetical } \\
\text { membrane protein }\end{array}$ & Unknown & -6.51 \\
\hline TK0636 & $\begin{array}{l}\text { Chemotaxis protein } \\
\text { CheC }\end{array}$ & $\begin{array}{l}\text { Environmental } \\
\text { information processing }\end{array}$ & -6.36 \\
\hline
\end{tabular}

(Continued)
TABLE T1B | Continued

\begin{tabular}{|c|c|c|c|}
\hline \multicolumn{4}{|l|}{ B } \\
\hline Transcript & Annotation & Process & Fold change \\
\hline TK0168 & $\begin{array}{l}\text { Predicted transcription } \\
\text { regulator, Lrp/AsnC } \\
\text { family }\end{array}$ & Transcription & -5.47 \\
\hline TK0546 & Hypothetical protein & Unknown & -5.32 \\
\hline TK0638 & $\begin{array}{l}\text { Methyl-accepting } \\
\text { chemotaxis protein }\end{array}$ & $\begin{array}{l}\text { Environmental } \\
\text { information processing }\end{array}$ & -5.21 \\
\hline TK1139 & $\begin{array}{l}\text { ATPase, AAA } \\
\text { superfamily }\end{array}$ & Unknown & -5.19 \\
\hline TK1804 & $\begin{array}{l}\text { ABC-type } \\
\text { dipeptide/oligopeptide } \\
\text { transport system, } \\
\text { probable periplasmic } \\
\text { component }\end{array}$ & Transport & -4.50 \\
\hline TK1606 & $\begin{array}{l}\text { Methyl-accepting } \\
\text { chemotaxis protein }\end{array}$ & $\begin{array}{l}\text { Environmental } \\
\text { information processing }\end{array}$ & -4.11 \\
\hline TK1605 & $\begin{array}{l}\text { Hydrolase, metallo- } \\
\text { beta-lactamase } \\
\text { superfamily }\end{array}$ & Unknown & -4.09 \\
\hline
\end{tabular}

for $5 \mathrm{~min}, \sim 200 \mu \mathrm{L}$ of the DNA-containing aqueous layer was precipitated by the addition of an equal volume of $1 \mathrm{M}$ Tris$\mathrm{HCl} \mathrm{pH} 8.0$ and 2.6 volumes of $100 \%$ ethanol proceeding a 1-h incubation at $-80^{\circ} \mathrm{C}$. DNAs were pelleted in a $4^{\circ} \mathrm{C}$ centrifuge at $10,000 \times \mathrm{g}$ for $30 \mathrm{~min}$ and subsequently resolved in a $4 \%$ agarose gel.

\section{RNA Isolation}

TS600 and TS622 were grown in triplicate to an optical density (measured at $600 \mathrm{~nm}$ ) of $\sim 0.5$ in liquid ASW-YT-S and used to inoculate (1:100) $300 \mathrm{ml}$ of ASW-YT-Pyr per strain and allowed to grow to an optical density (measured at $600 \mathrm{~nm}$ ) of $\sim 0.05$ to encourage chromatin reprograming. Cultures were rapidly chilled and pelleted at $8,000 \times \mathrm{g}$ for $5 \mathrm{~min}$ and then resuspended in $1.0 \mathrm{~mL}$ of Trizol (Invitrogen) with a 10-min incubation at room temperature. A total of $200 \mu \mathrm{l}$ of chloroform was added followed by centrifugation at $10,000 \times g$ at $4^{\circ} \mathrm{C}$ for 15 min yielding an RNA-containing aqueous layer which was added to $500 \mu \mathrm{l}$ of isopropanol and incubated at room temperature for $10 \mathrm{~min}$. Centrifugation at $10,000 \times g$ for $15 \mathrm{~min}$ at $4^{\circ} \mathrm{C}$ produced an RNA pellet that was washed with $1 \mathrm{ml}$ of $75 \%$ ethanol and subsequently resuspended in $88 \mu \mathrm{l}$ of RNase-free $\mathrm{H}_{2} \mathrm{O}, 10 \mu \mathrm{l}$ of DNaseI buffer, and $1 \mu l$ of DNaseI (New England Biolabs) to digest residual DNA $\left(37^{\circ} \mathrm{C}\right.$ for $\left.30 \mathrm{~min}\right)$. Replicate samples were prepared identically.

\section{RNA-Seq Library Preparation TS600 and TS622}

Using $\sim 120$ ng of RNA that was depleted of rRNA, following the NEBNext ${ }^{\circledast}$ rRNA Depletion Kit (E6310), cDNA libraries were constructed with New England Biolabs NEBNext ${ }^{\circledR}$ Ultra $^{\text {TM }}$ Directional RNA Library Prep kit for Illumina ${ }^{\circledR}$ (E7420s) and NEBNext $^{\circledR}$ Multiplex Oligos for Illumina ${ }^{\circledR}$ (Index primer set 1, E7335) according to the manufacturer's procedure. The multiplexed libraries were sequenced at Cofactor Genomics using 
TABLE T2A | Transcripts enriched and depleted in TS622 (TK1413G17D:histone A/TK2289WT :histone B) compared to TS600 (TK1413 ${ }^{W T}$ : histone A $\Delta$ TK2289:histone B). (A) All transcripts enriched in TS622 compared to TS600. Histone B, TK2289 denoted by * is absent in TS600 resulting in a large fold change. (B) The 30 most depleted transcripts in TS622 compared to TS600.

\begin{tabular}{|c|c|c|c|}
\hline Transcript & Annotation & Process & Fold change \\
\hline TK2289 & Archaeal histone B & Chromatin & 1565.20 \\
\hline TK1020 & $\begin{array}{l}\text { Hypothetical } \\
\text { membrane protein }\end{array}$ & Unknown & 3.49 \\
\hline TK0717 & $\begin{array}{l}\text { Molybdate transport } \\
\text { system } \\
\text { substrate-binding } \\
\text { protein }\end{array}$ & Transport & 2.93 \\
\hline TK0162 & $\begin{array}{l}\text { Hypothetical } \\
\text { membrane protein }\end{array}$ & Unknown & 2.69 \\
\hline TK0718 & $\begin{array}{l}\text { Molybdate transport } \\
\text { system permease } \\
\text { protein }\end{array}$ & Transport & 2.58 \\
\hline TK0720 & Hypothetical protein & Unknown & 2.55 \\
\hline TK0166 & Hypothetical protein & Unknown & 2.48 \\
\hline TK2070 & $\begin{array}{l}\text { Sulfhydrogenase } \\
\text { subunit delta }\end{array}$ & Energy Uetabolism & 2.45 \\
\hline TK1862 & Hypothetical protein & Unknown & 2.45 \\
\hline TK0467 & Hypothetical protein & Unknown & 2.42 \\
\hline TK2071 & $\begin{array}{l}\text { Sulfhydrogenase } \\
\text { subunit gamma (sulfur } \\
\text { reductase) }\end{array}$ & Energy metabolism & 2.37 \\
\hline TK0719 & $\begin{array}{l}\text { Molybdate transport } \\
\text { system ATP-binding } \\
\text { protein }\end{array}$ & Transport & 2.37 \\
\hline TK2072 & $\begin{array}{l}\text { Sulfhydrogenase } \\
\text { subunit beta (sulfur } \\
\text { reductase) }\end{array}$ & Energy metabolism & 2.33 \\
\hline TK0164 & $\begin{array}{l}\text { S-layer-like array } \\
\text { protein }\end{array}$ & Cell structure & 2.33 \\
\hline TK0163 & $\begin{array}{l}\text { ABC-2 type transport } \\
\text { system permease } \\
\text { protein }\end{array}$ & Transport & 2.27 \\
\hline TK1463 & Hypothetical protein & Unknown & 2.22 \\
\hline TK2278 & $\begin{array}{l}\text { Myo-inositol-1 } \\
\text {-phosphate synthase }\end{array}$ & Metabolism & 2.19 \\
\hline TK0765 & $\begin{array}{l}\text { Glyceraldehyde-3- } \\
\text { phosphate } \\
\text { dehydrogenase } \\
(\mathrm{NAD}(\mathrm{P}))\end{array}$ & Metabolism & 2.12 \\
\hline TK2069 & $\begin{array}{l}\text { Sulfhydrogenase } \\
\text { subunit alpha }\end{array}$ & Energy metabolism & 2.04 \\
\hline
\end{tabular}

one high output NextSeq Illumina ${ }^{\circledR}$ run for single-end reads with a minimum read length of $75 \mathrm{bp}$ and with a requested $>40$ million reads per sample.

\section{TS600 and TS620}

A total of $1.5 \mu \mathrm{g}$ of RNA was processed at Novogene for Prokaryotic RNA-seq, specifically for rRNA depletion (RiboZero $^{\mathrm{TM}}$ Magnetic Kit), library construction $\left(\mathrm{NEBNext}^{\circledR}{ }^{\circledR}\right.$ Ultra $^{\mathrm{TM}}$ RNA Library Prep kit) and 150 bp paired-end sequencing on a HiSeq Illumina ${ }^{\circledR}$ platform.
TABLE T2B |

B

\section{Transcript}

TK0038

TK0039

TK0040

TK0042

TK0041

TK0043

(K)

TK0812

TK0811

TK0631

TK0046

TK0044

Annotation
Archaeal flagellin B1
precursor
Archaeal flagellin B2
precursor

\section{Archaeal flagellin B3}

precursor

\section{Archaeal flag
precursor \\ Archaeal flage}

gellin B5

precursor

Archaeal

flagella-related

protein $\mathrm{C}$

\section{Adenylate kinase}

Hypothetical protein

Chemotaxis protein

methyltransferase

CheR

\section{Archaeal}

flagella-related

protein $\mathrm{G}$

Archaeal

flagella-related

protein $D$, internal

insertion

TK0045

Archaeal

flagella-related

protein $\mathrm{F}$

TK0156

Methyl-accepting

chemotaxis protein

TK0635

Chemotaxis histidine

\section{kinase}

TK0632

Chemotaxis protein

CheY

TK0630

Methyl-accepting

chemotaxis protein

TK0048

Archaeal

flagella-related

protein I, predicted

Csecretion ATPase

TK0633

Chemotaxis

protein-glutamate

methylesterase,

containing receiver

domain

TK0047

Archaeal

flagella-related

protein $\mathrm{H}$, predicted

ATPase

TK0049

Archaeal

flagella-related

membrane protein $\mathrm{J}$

TK0634

Sensor kinase CheA

TK0636

Chemotaxis protein

CheC

TK0050

Hypothetical protein

\section{Process}

Cell motility

Cell motility

Cell motility

Cell motility

Cell motility

Cell motility

Punne metabolism

Unknown

Environmental

information processing

Cell motility

Cell motility

$$
-9.76
$$

Cell motility

$$
-9.40
$$

Environmental

$-8.01$

information processing

Environmental

information processing

Environmental

$-7.27$

information processing

Environmental

$-7.20$

information processing

Cell motility

$-6.92$

Environmental

information processing

$$
-6.89
$$

Cell motility

Cell motility

Environmental

$-5.83$

information processing

Environmental

$-5.59$

information processing

Unknown 
TABLE T2B | Continued

\begin{tabular}{|c|c|c|c|}
\hline \multicolumn{4}{|l|}{ B } \\
\hline Transcript & Annotation & Process & Fold change \\
\hline TK2147 & $\begin{array}{l}\text { Methyl-accepting } \\
\text { chemotaxis protein }\end{array}$ & $\begin{array}{l}\text { Environmental } \\
\text { information processing }\end{array}$ & -5.19 \\
\hline TK0637 & $\begin{array}{l}\text { Chemotaxis protein } \\
\text { CheC }\end{array}$ & $\begin{array}{l}\text { Environmental } \\
\text { information processing }\end{array}$ & -5.07 \\
\hline TK0431 & $\begin{array}{l}\text { 5- } \\
\text { formaminoimidazole- } \\
\text { 4-carboxamide-1- } \\
\text { (beta)-D-ribofuranosyl } \\
\text { 5'-monophosphate } \\
\text { synthetase }\end{array}$ & Purine metabolism & -4.51 \\
\hline TK0638 & $\begin{array}{l}\text { Methyl-accepting } \\
\text { chemotaxis protein }\end{array}$ & $\begin{array}{l}\text { Environmental } \\
\text { information processing }\end{array}$ & -4.43 \\
\hline TK0432 & $\begin{array}{l}\text { Phosphonbosylam } \\
\text { inoimidazole- } \\
\text { succinocarboxamide } \\
\text { synthase }\end{array}$ & Purine metaboism & -4.26 \\
\hline TK1139 & $\begin{array}{l}\text { ATPase, AAA } \\
\text { superfamily }\end{array}$ & unknown & -4.23 \\
\hline TK0051 & $\begin{array}{l}\text { Protein-L- } \\
\text { isoaspartate(D- } \\
\text { aspartate) } \\
\text { O-methyltransferase }\end{array}$ & unknown & -4.01 \\
\hline
\end{tabular}

\section{Data Preprocessing TS600 and TS622}

RNA-Seq reads were first analyzed for quality control using FastQC (Andrews, 2010). To remove adapter sequences and other artifacts, fastx-trimmer was used to trim the first 11 positions in each read (Gordon). After filtering, the reads were aligned to the T. kodakarensis (KOD1) reference genome using bowtie (Langmead, 2010) with the parameter $-m 1$, thus ensuring suppression of all multiply aligned reads. Finally, the bowtie output was converted to BAM format, sorted, and indexed using samtools (Li et al., 2009).

\section{TS600 and TS620}

RNA-Seq reads were first analyzed for quality control using FastQC (Andrews, 2010). To remove adapter sequences and other artifacts, fastx-trimmer was used to trim the first 19 positions in each read (Gordon). After filtering, the reads were aligned to the T. kodakarensis (KOD1) reference genome using bowtie2 (Langmead and Salzberg, 2012) with default parameters. Next, in each library, reads that aligned to multiple locations were filtered out. Finally, the filtered output was converted to BAM format, sorted, and indexed using samtools (Li et al., 2009).

\section{Differential Gene Expression Analysis}

To identify differentially expressed genes we used EdgeR (Robinson et al., 2009). Read counts for every gene in the Ensembl annotations of the species were generated using a custom python script that used SpliceGrapher (Rogers et al., 2012) and pysam (Heger et al., 2014). The EdgeR p-values were adjusted for multiple comparisons using the Benjamini-Hochberg method
(Benjamini and Hochberg, 1995). Finally, we used a cutoff of 1.00 on the transcript abundance $(\log \mathrm{CPM})$ and fold change $(\log \mathrm{FC})$.

\section{Data Visualization and Plotting}

To visualize differential gene expression, we used Plotly (Sievert et al., 2017) to generate the MA plots. All analyses are provided in the supplementary jupyter notebooks. Circos (Krzywinski et al., 2009) plots were generated using the FPKM values of genes, measured using stringtie2 tool (Pertea et al., 2015) using the Ensembl gene annotations.

\section{DNA Sequencing of TS620}

Genomic DNA was purified from strain TS620 using the Monarch Genomic DNA Purification kit (New England Biolabs). Pacific Biosciences (PacBio) libraries were constructed following the Pacific Biosciences Template Preparation and Sequencing Protocol. The library was then sequenced on a PacBio Sequel instrument using Polymerase 3.0 Chemistry and diffusion loading for $600 \mathrm{~min}$. The data was analyzed using PacBio SMRT Analysis tools.

\section{RESULTS}

\section{A Single Histone Protein Is Sufficient for AHCP Formation}

To assess the role of chromatin superstructure, reflected by the totality of AHCPs, on gene expression in living cells, we generated T. kodakarensis strains that encode histone variants known to impact AHCP length. While strains retaining only a single histone isoform are viable, reducing the concentration of total histone proteins (Čuboňová et al., 2012; Mattiroli et al., 2017; Sanders et al., 2019b), or retaining histone variants with dramatically reduced DNA binding affinity (Čuboňová et al., 2012; Mattiroli et al., 2017) is not tolerated in T. kodakarensis. We thus carefully constructed strains wherein we retained the natural expression profile of one or both histone proteins but altered the sequence of individual histone-encoding genes to produce proteins at native levels (Mattiroli et al., 2017) that impact AHCP formation. Strains encoding only a single histone isoform in WT or variant form (Supplementary Figure S1) were generated, as were strains wherein one isoform remained WT, and the other was modified to replace G17 with D. Markerless modification or deletion of the genes encoding the endogenous histone proteins, HTkA (TK1413) and HTkB (TK2289), in their natural context allowed for preservation of the native promoter elements and did not impact the surrounding loci. Strain TS559 served as the parental strain for construction of three strains with varied histone compositions. Deletion of TK2289 (encoding HTkB) resulted in strain TS600 (encoding only HTkA ${ }^{W T}$ ). Modification of TK1413 to generate a G17D variant of HTkA in an otherwise native background, including the presense of WT HTkB, generated strain TS622. TS620 combines both genetic modifications, thereby generating a strain supported by only the synthesis of a single, G17D HTkA variant. Deletion of TK2289, encoding HTkB, was confirmed in TS600 
and TS620 by PCR amplification of the flanking genomic regions and sequencing to confirm the exact desired endpoints of the genomic modification (Supplementary Figure S1B). HTkA ${ }^{G 17 D}$ variants were confirmed in TS620 and TS622 by amplifying the entire HTkA coding and promoter sequences followed by Sanger sequencing to confirm retention of all native regulatory and coding sequences with the exception of the desired missense mutation (Supplementary Figures S1B,C).

To assess the impacts of varied histone isoforms on AHCP formation, total chromatin purified from strains TS600, TS620, and TS622 was subjected to micrococcal nuclease (MNase) digestion. MNase digestion provides a rapid, genome-wide mechanism to define minimal units of chromatin - such as the nucleosome in Eukarya. Digestion of chromatin isolated from TS600 confirmed the previously observed wildtype AHCP protection patterning - a prominent $\sim 60$ bp DNA fragment along with larger DNA fragments in increasing $\sim 30$ bp increments (up to $\sim 300 \mathrm{bp}$ ) - indicative of varied-length AHCPs (Čuboňová et al., 2012; Mattiroli et al., 2017; Henneman et al., 2018; Rojec et al., 2019; Henneman et al., 2020; Stevens et al., 2020) (Figures 1B,C). The persistence of the distinct $60+30(n)$ ladder demonstrates that AHCPs are varied in length but generally stable, thus providing architectures that can be exploited to regulate DNA accessibility and gene expression. TS600 encodes only the HTkA isoform, therefore all histonebased chromatin structure in this strain is composed of this single histone (Figure 1C).

In contrast, when HTkA was modified to place a larger and charged residue within the AGA motif of L1 (G17D), the chromatin from strain TS620 displayed a dramatically different MNase protection pattern (Figure 1B). Discrete DNA fragments $>90$ bp were absent, demonstrating histone:DNA interactions occurred to allow initial DNA wrapping but that continued polymerization to form extended AHCPs was not possible. The observed digestion pattern is consistent with previous (Mattiroli et al., 2017) digestions of chromatin from variant HTkA ${ }^{G 17}$ encoding strains, suggesting histone dimers form tetramers, protecting $\sim 60 \mathrm{bp}$ of DNA, and an additional dimer interacts to form a hexamer, protecting $\sim 90$ bp of DNA, but that larger associations of histone dimers are restricted due to clashes between adjacent gyres of AHCPs and loss of potential electrostatic interactions across the adjacent gyres (Henneman et al., 2018; Henneman et al., 2020; Bowerman et al., 2021). Thus, across the entire genome, the single $\mathrm{HTkA}^{G 17 D}$ variant encoded in TS620 disrupts the L1-L1 interface within AHCPs, preventing continued polymerization of histone dimers that normally provides a route to extended AHCP formation.

Surprisingly, digestion of total chromatin purified from TS622 resulted in an MNase protection pattern nearly identical to TS600 (Figure 1B) suggesting the presence of variant $\mathrm{HTkA}^{\text {G17D }}$ did not interfere with superhelix formation of the HTkB isoform. Given that chromatin from strain TS620 demonstrates HTkA ${ }^{G 17 D}$ alone cannot make up the superhelix, it is likely that all the larger regions of DNA protection in strain TS622 result from superstructures formed entirely of $\mathrm{HTkB}$. It is possible that at least some of the smaller (60-90 bp) protected DNA fragments result from chromatin structures composed entirely of
$\mathrm{HTkA}^{G 17 D}$ or from HTkB/HtkA ${ }^{G 17 D}$ heteromers; additionally, it is possible $\mathrm{HTkA}^{G 17 D}$ may cap or terminate the superhelices composed of $\mathrm{HTkB}$ resulting in protection of $>90 \mathrm{bp}$ fragments (Henneman et al., 2020; Stevens et al., 2020) (Figures 1B,C).

\section{AHCP Structures Regulate Genome-Wide Gene Expression}

With histone composition altered in strain TS622, and histonecomposition and extended AHCP formation disrupted in strain TS620, we sought to quantify the transcriptomes of each strain in response to an environmental shift (Jäger et al., 2014; Atomi and Reeve, 2019). Environmentally cued changes to histonebased chromatin architecture are a known mechanism to regulate gene expression, and for the Thermococcales, one of the largest determinants of metabolism and gene expression profiles is the availability of different terminal electron acceptors (Jäger et al., 2014; Mattiroli et al., 2017). Strains with variant histoneand AHCP-landscapes were grown to early exponential phase under conditions that permit elemental sulfur (So) to serve as the terminal-electron acceptor, then rapidly transferred to conditions wherein So was absent, signaling a metabolic shift requiring substantial changes in gene expression for continued rapid growth.

RNAs from each strain were purified from cultures following the environmental shift, depleted of ribosomal RNAs, and subjected to RNA-sequencing to quantify steady-state transcript abundance. RNAs were collected at early time points following the environmental shift to monitor the primary impacts of variant AHCP architectures on gene expression. Differential expression analyses defined meaningful changes in the transcriptomes of TS620 and TS622 compared to TS600 (Figure 2). Comparison of transcriptomes resultant from TS600 (HTkA ${ }^{W T}$ only; typical AHCPs of varied lengths) and TS620 (HTkA ${ }^{G 17 D}$ only; containing only short AHCPs) provides a quantitative measure of the regulation normally afforded by AHCPs in T. kodakarensis (Figures 1C, 2). In contrast, comparison of the transcriptomes of TS600 and TS622 $\left(\mathrm{HTkB}^{W T}\right.$, HTkA $\left.{ }^{G 17 D}\right)$ highlights the impact of histone variants on AHCPs that can regularly form with a mixture of $\mathrm{HTkB}$ and $\mathrm{HTkA}^{G 17 D}$ (Figures 1C, 2). Transcriptome changes were quantified by comparing $\log _{2}$ average fold change ( $\left.\log _{2} \mathrm{FC}\right)$ against log-average counts per million (LogCPM) (Figures 2B,C). The T. kodakarensis genome encodes $\sim 2,300$ annotated open reading frames, with abundant antisense transcription and many small transcripts (Fukui et al., 2005; Jäger et al., 2014; Sas-Chen et al., 2019). Our sequencing coverage was sufficient to detect nearly all transcripts with a $\operatorname{LogCPM}>1.00$ : 2,225 transcripts were included in the TS620/TS600 comparison; 2,231 transcripts were included in the TS622/TS600 comparison.

The substitution of HTkA ${ }^{G 17 D}$ (TS620) for HTkA ${ }^{W T}$ (TS600) as the only histone in T. kodakarensis resulted in significant (> 2-fold) changes in the steady-state abundance of 234 genes, representing $\sim 11 \%$ of the entire transcriptome. The lack of extended AHCPs in TS620 resulted in increased abundance of 100 genes and decreased abundance of another 134 genes (Figure 2A); genes with both ordinarily high or 
low expression were differentially expressed (Jäger et al., 2014). Genes-encoding proteins involved in central metabolism, purine synthesis and metabolism, amino acid synthesis, transport and a number of hypothetical proteins were upregulated (Table 1A). No obvious chromosomal distribution was noted, with the obvious exception of coregulation of operons, suggesting the entire chromosome is normally subject to regulation imposed by extended AHCPs. Further, hinting that expression of histone-encoding genes are regulated by AHCPs, TK1413 $17 D$ transcripts were enriched $\sim 2.8$ fold in TS620 compared to TK1413 ${ }^{W T}$ in TS600. Altered AHCP structures undoubtedly impact DNA replication, recombination and repair, and the loss of extended AHCPs results in the large increase in abundance of all three replication factor A proteins (archaeal RPA is a heterotrimer composed in T. kodakarensis of the products of TK1959 (increased $\sim 5.2$ fold), TK1960 (increased $\sim 5.8$ fold) and TK1961 (increased $\sim 4.8$ fold) in strain TS620. The likely increased abundance of functional RPA proteins suggests inhibiting extended AHCPs may permit some DNA regions to locally unwind or melt, thereby requiring more RPA to protect the increased abundance of single-stranded DNA (Figure 2B).

While many gene classes showed increases in transcript abundance due to changes in AHCP structure, a large percentage of genes related to cell motility and environmental signal sensing were downregulated in the absence of extended AHCPs in TS620 when compared to TS600. Localized AHCPs are likely to regulate gene expression both positively and negatively, depending on the availability of DNA sequences critical for gene expression. Expression of operons encoding archaellum components (annotated as the fla operon) and chemotaxis proteins (che operon) appear particularly sensitive to AHCPs and are likely dependent on AHCPs for proper regulation (Figure 2B). Genes comprising the entire T. kodakarensis archaellum-encoding fla operon (TK0038-TK0049) and chemotaxis-encoding che operon (TK0629-TK0639) were $\sim 7.1-65$-fold and $\sim 2.7-10$-fold less abundant in strain TS620 compared to strain TS600 (Table 1B).

Given that AHCPs can be generated in strain TS622 - as assessed by MNase digestions (Figure 1) - we predicted a more minor impact on the total transcriptome of strain TS622 compared to TS600. Despite the presence of $\mathrm{HTkA}^{G 17 D}$, the added presence of HTkB in TS622 permits sufficient AHCP formation to reduce the number of aberrantly transcribed genes when compared to TS620. When comparing the transcriptomes of TS622 (HTkA $\left.{ }^{G 17 D}, \mathrm{HTkB}\right)$ and TS600 (HTkA $\left.{ }^{W T}, \Delta \mathrm{HTkB}\right)$, we noted only approximately half as many transcripts (49) of decreased abundance in TS622, while just 18 transcripts were enriched (Figure 2C, Table 2A). Similar decreases in the abundance of transcripts encoding cell motility and environmental signal sensing were observed in TS622, with transcripts from the $\mathrm{fla}$ - and che-operon decreased $\sim 6-59$ fold and $\sim 2.6-9$-fold, respectively (Figure 2C, Table 2B). The decreased abundance of $f l a$ - and che-operon transcripts suggests the HTkA isoform is critical for proper regulation of these loci or factors that control expression of such loci and that the presence of $\mathrm{HTkB}^{W T}$ cannot compensate for the loss of $\mathrm{HTkA}^{W T}$ in these limited scenarios.

\section{AHCPs Are Necessary for Proviral Region Expression and Retention}

The T. kodakarensis genome contains 4 annotated, non-essential proviral regions, each $\sim 20-25 \mathrm{Kbp}$ in length: TKV1 (TK0073TK0105), TKV2 (TK0381-TK0421), TKV3 (TK0575-TK0614), and TKV4 (TK1342-TK1378) (Fukui et al., 2005; Tagashira et al., 2013). Comparisons of the genomes of many Thermococcales suggests recombination events between proviral regions can rearrange the genome context in evolutionary timescales; however, the proviral regions of the $T$. kodakarensis appear genetically stable (Krupovic et al., 2013; Cossu et al., 2015, 2017). These proviral regions represent $\sim 100 \mathrm{Kbp}$ in total ( $~ 5 \%$ of the $2.08 \mathrm{Mbp}$ genome) and encode a plethora of genes with unknown function. Expression of the proviral regions has been observed in all transcriptome studies of T. kodakarensis (Tagashira et al., 2013; Jäger et al., 2014). An observed trend in the transcriptomic profiles obtained from strain TS620 was the depletion or enrichment of genes assigned to the T. kodakarensis viral regions (Figures 2B,D). Several predicted integrase genes (TK0104 and TK0381) were upregulated in TS620 as well as the non-essential PCNA2 (Pan et al., 2013) (TK0582) and a predicted AAA superfamily ATPase (TK0601), (Supplementary Figures 3A,B). Most intriguing, transcripts aligning to a central portion of TKV2 (TK0390, TK0394-TK0410) were completely depleted from TS620. Among these genes were several predicted SpoVT, AbrB transcriptional regulators, and many hypothetical genes (TK0402, TK0405, TK0406, TK0409, and from TKV4, TK1372).

The observed complete absence of these TKV2 transcripts prompted further evaluation of the genome of TS620 (Figure 3). Whole-genome sequencing (WGS) of TS620 revealed a relatively large $(\sim 15 \mathrm{Kbp})$ central region of TKV2 was spontaneously excised from the genome (Figure 3B). Excision of most, but not all of TKV2 was confirmed by PCR amplifications of loci within and flanking TKV2 sequences in the genome of TS620 (Supplementary Figure S2). This missing region of TKV2 within strain TS620 genomic sequences aligns closely with the observed lack of reads aligning to TKV2 (Figure 3A). Despite differential expression of portions of other viral regions, the genomic loci for TKVR1, TKVR3, and TKVR4 remain intact (Supplementary Figure S3). The excision of TKV2 in only TS620 suggests not only are AHCP necessary for regulated gene expression, but that these structures also play a role in genome stability and recombination, perhaps related to viral region retention or repression.

\section{DISCUSSION}

Histone proteins encoded in most Archaea are the primary proteins responsible for genome organization (Nalabothula et al., 2013; Peeters et al., 2015; Henneman et al., 2018; Henneman et al., 2020; Sanders et al., 2019b; Stevens et al., 2020). Despite geometric and structural similarities, the potential for archaeal histones to form a continuous helical polymer is distinct from the eukaryotic nucleosome (Mattiroli et al., 2017). Formation of AHCPs is a major regulatory event in adaptive gene expression in $T$. kodakarensis and the regulation afforded by AHCP structures likely extends to most histone-encoding Archaea 


\section{A}

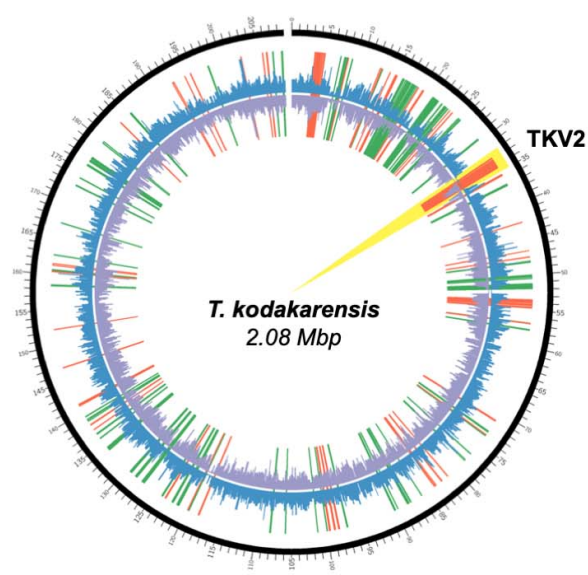

B

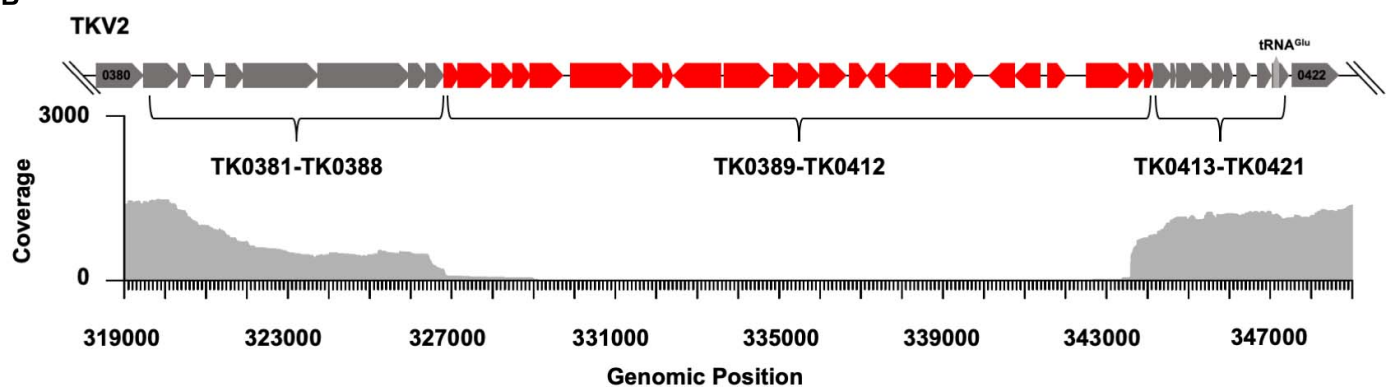

FIGURE 3 | Disruption of 3-dimensional chromatin structure results in genome instability in T. kodakarensis. (A) A circos plot comparing TS620 to TS600. The outermost black circle represents genomic position. The outer coverage plot (blue) represents Fragments Per Kilobase of transcript per Million mapped reads (FPKM) for TS620. The inner coverage plot (purple) represents FPKM for TS600. Notably, nearly zero reads mapped to TKVR2 in TS620 (highlighted in yellow). Red lines represent fragments enriched in TS600 while green lines represent fragments enriched in TS620. (B) A loci diagram of the annotated T. kodakarensis viral region 2 (TKVR2: TK0381-TK0421) that highlights the observed region of excision ( TK0389 - TK0412) superimposed over a genome alignment plot derived from PacBio long read sequencing of TS620.

(Bhattacharyya et al., 2018; Sanders et al., 2019b; Henneman et al., 2020; Stevens et al., 2020; Bowerman et al., 2021; Laursen et al., 2021).

The transcriptomes of $T$. kodakarensis strains that can (TS600 and TS622) and cannot generate extended AHCPs (TS620) reveal significant differences most likely associated directly with altered chromatin landscapes. The impacts are often dramatic, and the regulation is not associated with isolated chromosomal regions but instead is noted genome wide. In strain TS620, where formation of stable and detectable (via MNase digestions) AHCPs was inhibited, $>11 \%$ of the transcriptome was significantly altered. Approximately equal numbers of transcripts were more or less abundant due to the loss of AHCPs, suggesting that AHCPs can both positively and negatively impact gene expression, depending on the loci. Expression of the che- and fla-operons, as well as many proviral regions were the most dramatically affected by changes in the AHCP formation. In support of AHCP length influencing gene expression in these operons/proviral regions, expression profiles of $T$. kodakarensis strains encoding WT versions of a single histone isoform displayed no significant differences in the expression of these same operons (Čboňová et al., 2012).
AHCPs composed entirely of HTkA or HTkB are known to be sufficient for normal expression suggesting the presence of $\mathrm{HTkA}^{G 17 D}$ disrupts AHCP formation, thereby altering transcription in both TS620 and TS622. It is also plausible disrupted chromatin structures limit or increase expression of transcription factors that regulated select operon expression, but our transcriptomics data does not identify any obvious candidates.

Perhaps the most striking dysregulation observed in strains incapable of chromatin superhelix formation (TS620) was the loss of a portion of TKV2 from the genome. Like many proviral integrations in archaeal genomes, all four proviral regions in the $T$. kodakarensis genome overlap with tRNA encoding loci and large rearrangements noted in the genomes of $T$. kodakarensis and related Thermococcales often begin and end internal to the proviral regions (Geslin et al., 2007; Ortmann et al., 2008; Soler et al., 2008; Gonnet et al., 2011; Mochizuki et al., 2011; Gorlas et al., 2012; Tagashira et al., 2013). The combined impacts of disrupted AHCP formation on replication and recombination, the increased abundance of predicted viral integrase transcripts, and the potential for more ssDNA due to DNA melting in strains with altered chromatin 
landscapes provides a plausible explanation for the loss of TKV2 sequences. The inability to detect DNA sequences encompassing TK0389-0412 or viral particles containing these genes suggests this DNA fragment was degraded following excision from the genome (Soler et al., 2008). Although dispensable, the obvious growth defects of T. kodakarensis strains lacking proviral regions suggest their incorporation and proper regulation within archaeal genomes confers an evolutionary advantage (Hawkins et al., 2013; Tagashira et al., 2013).

The retention of histone proteins in most archaeal clades suggest histone-based chromatin structures provide beneficial regulatory roles that are exploited to provide a level of regulation on gene expression. The varied lengths of AHCPs, the presence of multiple histone isoforms in many Archaea, and the known changes in histone isoform expression in response to environmental changes all present routes to activate, repress and fine-tune gene expression to maximize growth in changing environments (Mattiroli et al., 2017; Bhattacharyya et al., 2018; Henneman et al., 2018; Henneman et al., 2020; Sanders et al., 2019b; Stevens et al., 2020). The potential for biologically significant post-translational modification of archaeal histones may provide an additional regulatory avenue (Alpha-Bazin et al., 2020).

The mechanisms controlling the formation of AHCPs with varying lengths at different loci and in different sequence contexts likely plays an additional role in transcription regulation (Henneman et al., 2018; Henneman et al., 2020; Sanders et al., 2019a,b, 2020; Stevens et al., 2020) and may be exploited by yet to be discovered archaeal chromatin remodeling complexes or histone isoforms that promote or inhibit formation of archaeal chromatin superstructures.

\section{DATA AVAILABILITY STATEMENT}

The datasets presented in this study have been deposited in the NIH GEO repository at https://www.ncbi.nlm.nig.gov and can be accessed with accession number GSE151920.

\section{AUTHOR CONTRIBUTIONS}

TSd, SF, RV, BB, and TSt designed, constructed, and confirmed the local genotypes of $T$. kodakarensis strains used in this work. TSd purified proteins, DNAs and RNAs, performed MNase digestions, generated RNA-seq libraries, analyzed data,

\section{REFERENCES}

Alpha-Bazin, B., Gorlas, A., Lagorce, A., Joulié, D., Boyer, J. B., Dutertre, M., et al. (2020). Lysine-specific acetylated proteome from the archaeon Thermococcus gammatolerans reveals the presence of acetylated histones. J. Proteomics 232:104044. doi: 10.1016/j.jprot.2020.104044

Andrews, S. (2010). FastQC: A Quality Control Tool for High Throughput Sequence Data. Available online at: http://www.bioinformatics.babraham.ac. uk/projects/fastqc/ built structural models, prepared figures, and helped write the manuscript. FU and AB-H analyzed RNA-sequencing datasets, prepared figures and helped write the manuscript. AGe and AGa prepared and sequenced DNA sequencing libraries, analyzed whole genome sequencing results, prepared figures, and helped write the manuscript. TSd and TSt prepared the initial manuscript that was edited, improved, and ultimately approved by all authors. All authors contributed to the article and approved the submitted version.

\section{FUNDING}

This work was supported by the National Institute of Health grant No. GM100329 (To TSt) and by funding from New England Biolabs, Inc. (To AGe and AGa).

\section{ACKNOWLEDGMENTS}

We thank members of the Santangelo, Ben-Hur, and Gardner labs for critical review of the manuscript.

\section{SUPPLEMENTARY MATERIAL}

The Supplementary Material for this article can be found online at: https://www.frontiersin.org/articles/10.3389/fmicb. 2021.681150/full\#supplementary-material

\begin{abstract}
Supplementary Figure 1 | Construction of TS600, TS620, and TS622. (A) Genomic loci diagrams for histone A (TK1413) and histone B (TK2289) and the modifications to each in strains TS600, TS620, and TS622 compared to parental strain TS559. (B) Amplification of TK1413 and TK2289 using the primers diagramed in (A). The open reading frame for TK2289 has been markerlessly deleted in both TS600 and TS620. Amplicons for TK1413 (lanes 1, 2, and 3) were sequence and (C) confirmed to contain either a glycine codon at position 17 (TS600) or aspartic acid (TS620 and TS622).
\end{abstract}

Supplementary Figure 2 | Viral region expression dysregulation results in the partial loss of TKV2. (A) All viral region transcripts enriched in TS620 when compared to TS600. (B) All viral region transcripts depleted in TS620 when compared to TS600. (C) Primer Pairs A/B, C/D, and E/F were used to amplify the upstream, downstream and central region of TKV2 in 1-TS600,

2-TS622, and 3-TS620.

Supplementary Figure 3 |TKV1, TKV3, and TKV4 remain stably integrated in the T. kodakarensis genome. TKV1 spans TK0073-TK0105. TKV3 spans TK0575-TK0614. TKV4 spans TK1342-TK1378.

Atomi, H., and Reeve, J. (2019). Microbe profile: Thermococcus kodakarensis: The modehyperthermophilic archaeon. Microbiol. (U. K.) 165, 1166-1168. doi: 10. 1099/mic. 0.000839

Benjamini, Y., and Hochberg, Y. (1995). Controlling the false discovery rate: a practical and powerful approach to multiple testing. J. R. Stat. Soc. Ser. B 57, 289-300. doi: 10.1111/j.2517-6161.1995.tb02031.x

Bhattacharyya, S., Mattiroli, F., and Luger, K. (2018). Archaeal DNA on the histone merry-go-round. FEBS J. 285, 3168-3174. doi: 10.1111/febs. 14495 
Bowerman, S., Wereszczynski, J., and Luger, K. (2021). Archaeal chromatin "slinkies" are inherently dynamic complexes with deflected DNA wrapping pathways. Elife 10:65587. doi: 10.7554/eLife.65587

Cossu, M., Badel, C., Catchpole, R., Gadelle, D., Marguet, E., Barbe, V., et al. (2017). Flipping chromosomes in deep-sea archaea. PLoS Genet. 13:e1006847. doi: 10.1371/journal.pgen.1006847

Cossu, M., Da Cunha, V., Toffano-Nioche, C., Forterre, P., and Oberto, J. (2015). Comparative genomics reveals conserved positioning of essential genomic clusters in highly rearranged Thermococcales chromosomes. Biochimie 118, 313-321. doi: 10.1016/j.biochi.2015.07.008

Čuboňová, L., Katano, M., Kanai, T., Atomi, H., Reeve, J. N., and Santangelo, T. J. (2012). An archaeal histone is required for transformation of Thermococcus kodakarensis. J. Bacteriol. 194, 6864-6874. doi: 10.1128/JB.01523-12

Decanniere, K., Babu, A. M., Sandman, K., Reeve, J. N., and Heinemann, U. (2000). Crystal structures of recombinant histones HMfA and HMfB from the hyperthermophilic archaeon Methanothermus fervidus. J. Mol. Biol. 303, 35-47. doi: 10.1006/jmbi.2000.4104

Dulmage, K. A., Todor, H., and Schmid, A. K. (2015). Growth-Phase-specific modulation of cell morphology and gene expression by an archaeal histone protein. MBio 6:e00649-15. doi: 10.1128/mBio.00649-15

Farkas, J. A., Picking, J. W., and Santangelo, T. J. (2013). Genetic techniques for the Archaea. Annu. Rev. Genet. 47, 539-561. doi: 10.1146/annurev-genet-111212133225

Fukui, T., Atomi, H., Kanai, T., Matsumi, R., Fujiwara, S., and Imanaka, T. (2005). Complete genome sequence of the hyperthermophilic archaeon Thermococcus kodakaraensis KOD1 and comparison with Pyrococcus genomes. Genome Res. 15, 352-363. doi: 10.1101/gr.3003105

Gehring, A., Sanders, T., and Santangelo, T. J. (2017). Markerless gene editing in the hyperthermophilic archaeon Thermococcus kodakarensis. Bio Prot. 7:2604. doi: 10.21769 /bioprotoc. 2604

Geslin, C., Gaillard, M., Flament, D., Rouault, K., Le Romancer, M., Prieur, D., et al. (2007). Analysis of the first genome of a hyperthermophilic marine viruslike particle, PAV1, isolated from Pyrococcus abyssi. J. Bacteriol. 189, 4510-4519. doi: 10.1128/JB.01896-06

Gonnet, M., Erauso, G., Prieur, D., and Le Romancer, M. (2011). PAMT11, a novel plasmid isolated from a Thermococcus sp. strain closely related to the viruslike integrated element TKV1 of the Thermococcus kodakaraensis genome. Res. Microbiol. 162, 132-143. doi: 10.1016/j.resmic.2010.11.003

Gordon, A. Unpublished. G. H.-F. Short-Reads Preprocessing Tools, and 2010, Undefined Fastx-Toolkit. Available online at: http://hannonlab.cshl.edu/fastx toolkit/

Gorlas, A., Koonin, E. V., Bienvenu, N., Prieur, D., and Geslin, C. (2012). TPV1, the first virus isolated from the hyperthermophilic genus Thermococcus. Environ. Microbiol. 14, 503-516. doi: 10.1111/j.1462-2920.2011.02662.x

Hawkins, M., Malla, S., Blythe, M. J., Nieduszynski, C. A., and Allers, T. (2013). Accelerated growth in the absence of DNA replication origins. Nature 503, 544-547. doi: 10.1038/nature12650

Heger, A., Belgrad, T. G., Goodson, M., and Jacobs, K. (2014). pysam: Python interface for the SAM/BAM sequence alignment and mapping format. Available online at: https://github.com/pysam-developers/pysam (accessed February 1, 2016).

Henneman, B., Brouwer, T. B., Erkelens, A. M., Kuijntjes, G.-J., van Emmerik, C., van der Valk, R. A., et al. (2020). Mechanical and structural properties of archaeal hypernucleosomes. Nucleic Acids Res. 21:gkaa1196. doi: 10.1093/nar/ gkaa1196

Henneman, B., van Emmerik, C., van Ingen, H., and Dame, R. T. (2018). Structure and function of archaeal histones. PLoS Genet. 14:e1007582. doi: 10.1371/ journal.pgen.1007582

Jäger, D., Förstner, K. U., Sharma, C. M., Santangelo, T. J., and Reeve, J. N. (2014). Primary transcriptome map of the hyperthermophilic archaeon Thermococcus kodakarensis. BMC Genom. 15:684. doi: 10.1186/1471-2164-15-684

Krupovic, M., Gonnet, M., Hania, W., Ben Forterre, P., and Erauso, G. (2013). Insights into dynamics of mobile genetic elements in hyperthermophilic environments from five new Thermococcus plasmids. PLoS One 8:e49044. doi: 10.1371/journal.pone.0049044

Krzywinski, M., Schein, J., Birol, I., Connors, J., Gascoyne, R., Horsman, D., et al. (2009). Circos: An information aesthetic for comparative genomics. Genome Res. 19, 1639-1645. doi: 10.1101/gr.092759.109
Langmead, B. (2010). Aligning short sequencing reads with Bowtie. Curr. Protoc. Bioinforma Chapter 11, Unit 11.7. doi: 10.1002/0471250953.bi1107s32

Langmead, B., and Salzberg, S. L. (2012). Fast gapped-read alignment with Bowtie 2. Nat. Methods 9, 357-359. doi: 10.1038/nmeth.1923

Laursen, S. P., Bowerman, S., and Luger, K. (2021). Archaea: the final frontier of chromatin. J. Mol. Biol. 433, 166791. doi: 10.1016/j.jmb.2020.166791

Li, H., Handsaker, B., Wysoker, A., Fennell, T., Ruan, J., Homer, N., et al. (2009). The sequence alignment/map format and SAMtools. Bioinformatics 25, 20782079. doi: 10.1093/bioinformatics/btp352

Luger, K., Mäder, A. W., Richmond, R. K., Sargent, D. F., and Richmond, T. J. (1997). Crystal structure of the nucleosome core particle at $2.8 \AA$ resolution. Nature 389, 251-260. doi: 10.1038/38444

Mattiroli, F., Bhattacharyya, S., Dyer, P. N., White, A. E., Sandman, K., Burkhart, B. W., et al. (2017). Structure of histone-based chromatin in Archaea. Science 357, 609-612. doi: 10.1126/science.aaj1849

Mochizuki, T., Sako, Y., and Prangishvili, D. (2011). Provirus induction in hyperthermophilic archaea: characterization of Aeropyrum pernix spindleshaped virus 1 and Aeropyrum pernix ovoid virus 1. J. Bacteriol. 193, 5412-5419. doi: 10.1128/JB.05101-11

Nalabothula, N., Xi, L., Bhattacharyya, S., Widom, J., Wang, J. P., Reeve, J. N., et al. (2013). Archaeal nucleosome positioning in vivo and in vitro is directed by primary sequence motifs. BMC Genomics 14:391. doi: 10.1186/1471-2164-14391

Nishida, H., and Oshima, T. (2017). Archaeal histone distribution is associated with archaeal genome base composition. J. Gen. Appl. Microbiol. 63, 28-35. doi: 10.2323/jgam.2016.07.003

Ortmann, A. C., Brumfield, S. K., Walther, J., McInnerney, K., Brouns, S. J. J., van de Werken, H. J. G., et al. (2008). Transcriptome analysis of infection of the archaeon Sulfolobus solfataricus with sulfolobus turreted icosahedral virus. J. Virol. 82, 4874-4883. doi: 10.1128/jvi.02583-07

Pan, M., Santangelo, T. J., Čuboňová, L., Li, Z., Metangmo, H., Ladner, J., et al. (2013). Thermococcus kodakarensis has two functional PCNA homologs but only one is required for viability. Extremophiles 17, 453-461. doi: 10.1007/ s00792-013-0526-8

Peeters, E., Driessen, R. P. C., Werner, F., and Dame, R. T. (2015). The interplay between nucleoid organization and transcription in archaeal genomes. Nat. Rev. Microbiol. 13, 333-341. doi: 10.1038/nrmicro3467

Pertea, M., Pertea, G. M., Antonescu, C. M., Chang, T.-C., Mendell, J. T., and Salzberg, S. L. (2015). StringTie enables improved reconstruction of a transcriptome from RNA-seq reads. Nat. Biotechnol. 33, 290-295. doi: 10.1038/ nbt. 3122

Robinson, M. D., McCarthy, D. J., and Smyth, G. K. (2009). edgeR: A Bioconductor package for differential expression analysis of digital gene expression data. Bioinformatics 26, 139-140. doi: 10.1093/bioinformatics/ btp616

Rogers, M. F., Thomas, J., Reddy, A. S. N., and Ben-Hur, A. (2012). SpliceGrapher: Detecting patterns of alternative splicing from RNA-Seq data in the context of gene models and EST data. Genome Biol. 13:1186. doi: 10.1186/gb-2012-13-1r4

Rojec, M., Hocher, A., Stevens, K. M., Merkenschlager, M., and Warnecke, T. (2019). Chromatinization of escherichia coli with archaeal histones. Elife 8:49038. doi: 10.7554/eLife.49038

Sanders, T. J., Lammers, M., Marshall, C. J., Walker, J. E., Lynch, E. R., and Santangelo, T. J. (2019a). TFS and Spt4/5 accelerate transcription through archaeal histone-based chromatin. Mol. Microbiol. 111, 784-797. doi: 10.1111/ mmi.14191

Sanders, T. J., Marshall, C. J., and Santangelo, T. J. (2019b). The role of archaeal chromatin in transcription. J. Mol. Biol. 431, 4103-4115. doi: 10.1016/j.jmb. 2019.05.006

Sanders, T. J., Wenck, B. R., Selan, J. N., Barker, M. P., Trimmer, S. A., Walker, J. E., et al. (2020). FttA is a CPSF73 homologue that terminates transcription in Archaea. Nat. Microbiol. 5, 545-553. doi: 10.1038/s41564-0200667-3

Sandman, K., and Reeve, J. N. (2000). Structure and functional relationships of archaeal and eukaryal histones and nucleosomes. Arch. Microbiol. 173, 165-169. doi: $10.1007 / \mathrm{s} 002039900122$ 
Sandman, K., and Reeve, J. N. (2001). Chromosome packaging by archaeal histones. Adv. Appl. Microbiol. 50, 73-99. doi: 10.1016/s0065-2164(01)5 0004-0

Sandman, K., and Reeve, J. N. (2006). Archaeal histones and the origin of the histone fold. Curr. Opin. Microbiol. 9, 520-525. doi: 10.1016/j.mib.2006.08.003

Santangelo, T. J., Cubonova, L., Skinner, K. M., and Reeve, J. N. (2009). Archaeal intrinsic transcription termination in vivo. J. Bacteriol. 191, 7102-7108. doi: 10.1128/JB.00982-09

Sas-Chen, A., Thomas, J., Matzov, D., Taoka, M., Nance, K., Nir, R., et al. (2019). Dynamic RNA acetylation revealed by cross-evolutionary mapping at base resolution. Nature 583, 638-643.

Sievert, C., Parmer, C., Hocking, T., and Chamberlain, S. (2017). plotly: Create Interactive Web Graphics via 'plotly.js'. R package version 4.7.1. Available online at: https://CRAN.R-project.org/package=plotly

Soares, D. J., Sandman, K., and Reeve, J. N. (2000). Mutational analysis of archaeal histone-DNA interactions. J. Mol. Biol. 297, 39-47. doi: 10.1006/jmbi.2000. 3546

Soler, N., Marguet, E., Verbavatz, J. M., and Forterre, P. (2008). Virus-like vesicles and extracellular DNA produced by hyperthermophilic archaea of the order Thermococcales. Res. Microbiol. 159, 390-399. doi: 10.1016/j.resmic.2008.04. 015

Stevens, K. M., Swadling, J. B., Hocher, A., Bang, C., Gribaldo, S., Schmitz, R. A., et al. (2020). Histone variants in archaea and the evolution of combinatorial chromatin complexity. Proc. Natl. Acad. Sci. U.S.A. 117, 33384-33395. doi: 10.1073/pnas.2007056117

Tagashira, K., Fukuda, W., Matsubara, M., Kanai, T., Atomi, H., and Imanaka, T. (2013). Genetic studies on the virus-like regions in the genome of hyperthermophilic archaeon, Thermococcus kodakarensis. Extremophiles 17, 153-160. doi: 10.1007/s00792-012-0504-6

Wilkinson, S. P., Ouhammouch, M., and Geiduschek, E. P. (2010). Transcriptional activation in the context of repression mediated by archaeal histones. Proc. Natl. Acad. Sci. U.S.A. 107, 6777-6781. doi: 10.1073/pnas.1002 360107

Zaremba-Niedzwiedzka, K., Caceres, E. F., Saw, J. H., Bäckström, D., Juzokaite, L., Vancaester, E., et al. (2017). Asgard archaea illuminate the origin of eukaryotic cellular complexity. Nature 541, 353-358. doi: 10.1038/nature21031

Conflict of Interest: AGe and AGa are employed and funded by New England Biolabs, Inc. New England Biolabs is a manufacturer and vendor of molecular biology reagents, including DNA replication and repair enzymes. This affiliation does not affect the authors' impartiality, objectivity of data generation or its interpretation, adherence to journal standards and policies or availability of data.

The remaining authors declare that the research was conducted in the absence of any commercial or financial relationships that could be construed as a potential conflict of interest.

Copyright (c) 2021 Sanders, Ullah, Gehring, Burkhart, Vickerman, Fernando, Gardner, Ben-Hur and Santangelo. This is an open-access article distributed under the terms of the Creative Commons Attribution License (CC BY). The use, distribution or reproduction in other forums is permitted, provided the original author(s) and the copyright owner(s) are credited and that the original publication in this journal is cited, in accordance with accepted academic practice. No use, distribution or reproduction is permitted which does not comply with these terms. 